\title{
Study of bioaccessibility of cobalt species in berries and seeds by mass spectrometry techniques
}

\author{
Justyna Wojcieszek and Lena Ruzik (D)
}

\begin{abstract}
In recent years, açai berries (Euterpe Oleracea M.), goji berries (Lycium barbarum L.), bilberries (Vaccinium myrtillus L.), and chia seeds (Salvia hispanica L.) have increased interest worldwide due to their nutritional value and health benefits. In the present study, SEC-ICP-MS and $\mu$-HPLC-ESI-MS/MS were used for the investigation of cobalt speciation and evaluation of its bioaccessibility in these products. Total cobalt content was determined, and açai berries $\left(0.348 \pm 0.042 \mu \mathrm{g} \mathrm{g}^{-1}\right)$ and chia seeds $\left(0.352 \pm 0.036 \mu \mathrm{g} \mathrm{g}^{-1}\right)$ were found as the best sources of this element. Different elution profiles of the extracts of examined berries and seeds obtained with the use of ammonium acetate, Tris- $\mathrm{HCl}$, and SDS suggested that cobalt is bound by different bioligands in each biomatrix.

The bioaccessibility of cobalt species was evaluated by SEC-ICP-MS. On the chromatograms of extracts obtained after simulation of gastrointestinal digestion, peaks corresponding to low molecular mass (17.00-1.35 kDa) cobalt complexes were observed. In the case of goji berries, their intensities were significantly higher on chromatograms of gastrointestinal than gastric extract. In enzymatic extracts, different forms of vitamin $\mathrm{B}_{12}$ were identified by $\mu$ HPLC-ESI-MS, including its natural forms-methylcobalamin (Me-Cbl) and adenosylcobalamin (Ado-Cbl).
\end{abstract}

Keywords: In vitro digestion method, Cobalt complexes, Vitamin $B_{12}$, HPLC, ICP MS, ESI MS

\section{Introduction}

Cobalt is an essential element for plants, animals, and human beings, needed in a small amount in the diet to conduct its daily requirement. As an integral part of the only metal-containing vitamin, $\mathrm{B}_{12}$, cobalt plays an important role in some biochemical processes, e.g., synthesis of nucleic acids and amino acids (Adolfo et al. 2016; Stoica et al. 2004). Vitamin $B_{12}$ or cobalamin is an essential vitamin for the human organism, stored in the liver. It can occur in different forms but only methylcobalamin (Me- $\mathrm{Cbl})$, hydroxocobalamin $(\mathrm{OH}-\mathrm{Cbl})$, and adenosylcobalamin (Ado-Cbl) are its natural forms (Bosle et al. 2016; Kumar et al. 2010). Cyanocobalamin is a man-made form of vitamin $B_{12}$, supplied by food supplements or fortified food, used to prevent and treat low blood levels of this

\footnotetext{
* Correspondence: lenka@ch.pw.edu.pl

Chair of Analytical Chemistry, Faculty of Chemistry, Warsaw University of Technology, Noakowskiego 3, 00-664 Warsaw, Poland
}

vitamin (Indyk et al. 2017). Speciation analysis of cobalt in food is usually limited to the determination of vitamin $B_{12}$ and its derivatives. It is important to mention that different chemical forms of metal may be beneficial or toxic for human organism (Intawongse and Dean 2006).

Studies concerning chemical speciation of elements in food are needed for a more accurate evaluation of biological availability or toxicity of the element in the diet (Koplík et al. 2002a). Usually, analytical methods for trace element speciation are based on the combination of effective separation method (mainly liquid chromatography or electrophoresis) and element-specific detection, most often realized by inductively coupled plasma mass spectrometry (Koplík et al. 2002b; Szpunar and Łobiński 2002).

Size exclusion chromatography (SEC), used in this study, is especially suitable for separation of element species of limited stability, for example in protein-rich matrices, as in the case of Spirulina (Arthrospira

\section{Springer Open}

(๑) The Author(s). 2020 Open Access This article is licensed under a Creative Commons Attribution 4.0 International License, which permits use, sharing, adaptation, distribution and reproduction in any medium or format, as long as you give appropriate credit to the original author(s) and the source, provide a link to the Creative Commons licence, and indicate if changes were made. The images or other third party material in this article are included in the article's Creative Commons licence, unless indicated otherwise in a credit line to the material. If material is not included in the article's Creative Commons licence and your intended use is not permitted by statutory regulation or exceeds the permitted use, you will need to obtain permission directly from the copyright holder. To view a copy of this licence, visit http://creativecommons.org/licenses/by/4.0/. 
platensis G.) (Wojcieszek et al. 2015). The main advantage of SEC can be seen in the simplicity of application (Koplík et al. 2002a; Koplík et al. 2002b). SEC-ICP-MS (inductively coupled plasma mass spectrometry) has been successfully applied in the study of cobalt species in various samples, such as soybean flour (Koplík et al. 2002b), seeds of legumes (Koplík et al. 2002a), goldenberries (Wojcieszek and Ruzik 2016a), noni juice (Rybak and Ruzik 2013), Brazil nuts (Kannamkumarath et al. 2004), eggs (Lipiec et al. 2012; Lipiec et al. 2011), or even compost (Sadi et al. 2002). However, in a great number of already published works, studies of trace elements in food and food supplements are based mainly on the establishment of their total concentration what is not enough in terms of information regarding the fraction that is potentially bioaccessible for the human organism. Only a part of the total content of trace elements present in the food matrix can be absorbed and utilized by the human body (Khouzam et al. 2011). Therefore, beyond the determination of the total content in a food product, studies of metals should also consider their bioaccessibility (Peixoto et al. 2016).

Bioaccessibility includes all physical, chemical, and microbiological processes between chewing in the mouth and precipitation in the intestines in the human body. Knowledge about the bioaccessibility value, described as the amount dissolved in the digestive tract, is necessary to determine the bioavailability value, known as the amount of the substance that reaches the bloodstream (Altundag et al. 2015; Ng et al. 2015).

Vitamin $B_{12}$ is well-known to be the sole vitamin that is absent from plant-derived food sources. Foods (meat, milk, eggs, fish, and shellfish) derived from animals are the major dietary sources of vitamin $B_{12}$ (Watanabe 2007). Edible plants and mushrooms rarely contain a considerable amount of vitamin $B_{12}$, mainly due to concomitant bacteria in soil and/or their aerial surfaces (Watanabe and Bito 2018). However, some investigation confirmed the presence of $B_{12}$ in plant food (Nakos et al. 2016) and show the vitamin $\mathrm{B}_{12}$-containing plant-derived food: fermented soybean $(0.7-8.0 \mu \mathrm{g} / 100 \mathrm{~g})$, broccoli (trace amount), asparagus (trace amount), various types of tea leaves (0.1$1.2 \mu \mathrm{g} / 100 \mathrm{~g}$ ), wild edible mushroom (approx. $0.09 \mu \mathrm{g} / 100$ $\mathrm{g}$ ), and edible algae (approx. 63.6 $\mu \mathrm{g} / 100 \mathrm{~g}$ ) (Watanabe et al. 2014). Food products chosen for the present study are recently more and more popular, due to their nutritional value and health benefits. They are important sources of proteins, minerals, antioxidants, and vitamins; contain a lot of biologically active compounds; and may reduce the risk of various diseases (Chu et al. 2010; Heinrich et al. 2011; Muñoz et al. 2013; Namiesnik et al. 2013; Wang et al. 2010; Wojcieszek and Ruzik 2016b).

To the best of our knowledge, there are no data reported so far regarding the characterization of cobalt species in berries and chia seeds. Therefore, the aims of the presented study were (i) to determine cobalt content in analyzed samples and evaluate to what extent their daily consumption fulfills the recommended daily intake for this element, (ii) to separate extracted cobaltcontaining species on SEC column coupling with ICP MS detector, (iii) to evaluate the bioaccessibility of cobalt present in analyzed samples by an in vitro digestion method, and (iv) to confirm the presence of vitamin $B_{12}$ in extracts obtained after simulation of digestion using $\mu$-HPLC-ESI-MS/MS ( $\mu$-high-performance liquid chromatography/electrospray ionization tandem mass spectrometry).

\section{Materials and methods}

\section{Chemicals and materials}

Most of the reagents used during analysis were of analytical reagent grade purchased from Sigma-Aldrich (Sigma-Aldrich, Buchs, Switzerland). The nitric acid of purity for trace metal analysis was purchased from Fluka (Switzerland). The formic acid of LC/MS purity was obtained from Fisher Scientific (Fair Lawn, NJ, USA). Methanol was purchased from $\mathrm{POCH}$ (Gliwice, Poland). Pepsin from porcine gastric mucosa and pancreatin from porcine pancreas were of biological grade (Sigma-Aldrich, Buchs, Switzerland). Deionized water $(18 \mathrm{M} \Omega \mathrm{cm})$ prepared with a Milli-Q system (Millipore Elix 3, Millipore, Saint-Quentin, France) was used throughout. The SEC column was calibrated using the size exclusion standard (BIO-RAD, Warsaw, Poland). The calibration curves were prepared using a solution of Environmental Spike Mix (1000 mg L ${ }^{-1}$ of Fe, K, Ca, Na, Mg and 100 $\mathrm{mg} \mathrm{L}^{-1}$ of $\mathrm{Ag}, \mathrm{Al}, \mathrm{As}, \mathrm{Ba}, \mathrm{Be}, \mathrm{Cd}, \mathrm{Co}, \mathrm{Cr}, \mathrm{Cu}, \mathrm{Mn}, \mathrm{Mo}$, $\mathrm{Ni}, \mathrm{Pb}, \mathrm{Sb}, \mathrm{Se}, \mathrm{Tl}, \mathrm{V}, \mathrm{Zn}, \mathrm{U}$; matrix $5 \% \mathrm{HNO}_{3}$ ) purchased from Agilent Technologies.

\section{Instrumentation}

Samples of extracts were injected on a Superdex200 10/ 300GL (GE Healthcare Life Sciences) exclusion column which was coupled to the ICP-MS instrument by directly connecting the column outlet to the cross-flow nebulizer through a PEEK tubing. Chromatographic separations were performed using Agilent 1100 gradient HPLC pump (Agilent Technologies, Waldbronn, Germany) as the sample delivery system. Buffer solution of $10 \mathrm{mM}$ ammonium acetate ( $\mathrm{pH}$ 7.4) served as the mobile phase, and the flow rate was fixed on $0.7 \mathrm{~mL} \mathrm{~min}^{-1}$. Calibration of SEC column was accomplished with a standard mixture of thyroglobulin $(670 \mathrm{kDa}) t_{\mathrm{r}}=11.8 \mathrm{~min}, \gamma$-globulin $(158 \mathrm{kDa}) t_{\mathrm{r}}=14.8 \mathrm{~min}$, ovalbumin $(44 \mathrm{kDa}) t_{\mathrm{r}}=21.4$ min, myoglobin $(17 \mathrm{kDa}) t_{\mathrm{r}}=27.3 \mathrm{~min}$, and vitamin $\mathrm{B}_{12}$ $(1.35 \mathrm{kDa}) t_{\mathrm{r}}=30.2 \mathrm{~min}$.

An Agilent 7500a ICP MS (Tokyo, Japan) was used as a detection system for the Agilent 1100 HPLC system 
and as an element-specific detector for quantification of total metal content in analyzed samples. Ni-skimmer was installed in the interface; the position of the torch and nebulizer gas flow was adjusted each day of work. The optimum performance of the apparatus was found with particular attention for the lowest level $(\leq 0.2 \%)$ of polyatomic oxide interferences-to reduce the possibility of occurrence of cobalt interferences $\left({ }^{43} \mathrm{Ca}^{16} \mathrm{O}^{+}\right.$, ${ }^{42} \mathrm{Ca}^{16} \mathrm{O}^{1} \mathrm{H}^{+}$and $\left.{ }^{40} \mathrm{Ar}^{18} \mathrm{O}^{1} \mathrm{H}^{+}\right)$. The instrument working conditions were optimized daily using a $10 \mu \mathrm{g} \mathrm{L} \mathrm{L}^{-1}$ solution of ${ }^{7} \mathrm{Li}^{+},{ }^{89} \mathrm{Y}^{+}$, and ${ }^{209} \mathrm{Bi}^{+}$in $2 \% \mathrm{HNO}_{3}$, with a dwell time of $0.1 \mathrm{~ms}$ for each isotope.

$\mu$-HPLC-ESI-MS analysis was performed using Agilent 1200 series chromatograph (Agilent Technology, Waldbronn, Germany) equipped with a binary capillary pump, degasser, autosampler, thermostatically controlled column compartment, and capillary Zorbax SB C18 column coupled to electrospray ionization triple quadrupole mass spectrometer (Agilent 6460 Triple Quad LC/MS, Agilent Technologies, Santa Clara, CA, USA). All the operations, acquiring, and analysis of data were processed by the MassHunter Software (Agilent Technology, USA).

Operational parameters are summarized in Table 1.

A Bandelin Sonorex Model 1210 ultrasonic bath (Germany) and MPW Model 350R centrifuge (MPW, Poland) were used for extraction procedures. Microwave digestion with a Speedwave ${ }^{\circ}$ four Berghof system (Germany) was used for mineralization of samples. A thermostatically controlled water bath (Memmert WB 10 , Germany) was used during simulation of digestion.

\section{The samples and sample preparation}

Frozen bilberries (Vaccinium myrtillus L., harvested in Poland in 2012) were stored at $-20^{\circ} \mathrm{C}$ until analysis. The lyophilized Brazilian açai berries (Euterpe oleracea Mart.) and chia seeds (Salvia hispanica L.) were obtained from KenayAG, Poland (imported from Brazil and Peru, respectively). The chia seeds and bilberries were lyophilized and ground using agate mortar and pestle until a homogenous powder was formed; the powder was stored at room temperature. The dried goji berries (Lycium Barbarum L.) were obtained from Sante, Poland, (imported from China) and ground in liquid nitrogen with agate mortar and pestle, in the same way with chia seeds and bilberries.

\section{Sample mineralization for determination of the total amount of cobalt}

Samples for the determination of total cobalt content were prepared by microwave-assisted mineralization. Three replications of each sample were precisely weighed (c.a. $0.2 \mathrm{~g}$ of dry mass) and transferred to PTFE (polytetrafluoroethylene) vessels, and a mixture of $5 \mathrm{~mL}$ of $69 \% \mathrm{HNO}_{3}$ and $3 \mathrm{~mL}$ of $30 \% \mathrm{H}_{2} \mathrm{O}_{2}$ was added. Then, the digestion was carried out. After cooling down, obtained solutions were diluted to a final volume of 25 $\mathrm{mL}$ with $\mathrm{MQ}$ water. Further dilutions were prepared just before ICP-MS analysis with $2 \% \mathrm{HNO}_{3}$ containing yttrium of concentration $10 \mathrm{ng} \mathrm{mL}^{-1}$ used as an internal standard (Połeć-Pawlak et al. 2007). The multi-element standard solution was chosen for calibration. Concentrations of elements were determined by ICP-MS using the external calibration curve. Calibration graphs were obtained for cobalt concentrations within the range 0.1$10.0 \mathrm{ng} \mathrm{mL}^{-1}$, and they were linear in this range from $0.2 \mathrm{ng} \mathrm{mL}^{-1}$ to $10.0 \mathrm{ng} \mathrm{mL}^{-1}$ with $r^{2}$ above 0.998 .

\section{Extraction of cobalt species from analyzed samples}

For the extraction of cobalt compounds, the following solutions were used: $10 \mathrm{mM}$ ammonium acetate $(\mathrm{pH}$ 6.8), $30 \mathrm{mM}$ Tris- $\mathrm{HCl}$ ( $\mathrm{pH} 7.4$ ), and $2 \%$ sodium dodecyl sulfate (SDS) in water. Samples of analyzed food products $(0.05 \mathrm{~g}$ of dry powder) were weighted and extracted with $2.0 \mathrm{~mL}$ of each solvent for $1 \mathrm{~h}$ using an ultrasonic bath. The obtained solutions were next centrifuged for $20 \mathrm{~min}$ at $15,000 \mathrm{rpm}$ at $15^{\circ} \mathrm{C}$. The final supernatants were filtered with 0.45 - $\mu \mathrm{m}$ syringe filter (Sigma-Aldrich, Bellefonte, PA, USA), two first drops were discarded, and only the remaining part of the filtrates was injected on the size exclusion column (Rybak and Ruzik 2013).

\section{In vitro gastrointestinal digestion studies}

The in vitro digestion method used in the study was based on that described by Luten et al. (1987), modified and adapted for the samples being studied. Simulation of gastric digestion was initiated by $2.5 \mathrm{~mL}$ of pepsin solution $(6 \% \mathrm{w} / \mathrm{v}$ pepsin in $0.15 \mathrm{M} \mathrm{NaCl}$, acidified by $\mathrm{HCl}$ to $\mathrm{pH} 1.8$ ) added to $0.05 \mathrm{~g}$ of sample. After $15 \mathrm{~min}$ of sonication (initial degassing), samples were incubated for 3.5 $\mathrm{h}$ at $37^{\circ} \mathrm{C}$, followed by centrifugation ( $20 \mathrm{~min}, 15,000$ $\mathrm{rpm}, 4^{\circ} \mathrm{C}$ ) and filtration through $0.45-\mu \mathrm{m}$ syringe filters. For intestinal digestion, $2.5 \mathrm{~mL}$ of pancreatin solution was added to the gastric digests (after adjustment to neutral $\mathrm{pH}$ ) and sonicated for $15 \mathrm{~min}$. Then, mixtures were incubated for $2 \mathrm{~h}$ at $37^{\circ} \mathrm{C}$, followed by centrifugation and filtration as in the case of gastric digestion. Both supernatants were analyzed by SEC-ICP-MS. In the next step, gastric and gastrointestinal extracts were ultracentrifuged through filters with a molecular mass cutoff of $3 \mathrm{kDa}$ before $\mu$-HPLC-ESI-MS analysis to separate enzymatic proteins from small molecular mass compounds (Howlett et al. 2006).

\section{Results and discussion}

The total concentration of cobalt in analyzed berries and seeds

The total content of cobalt was determined using ICPMS, after microwave-assisted digestion of samples. Results were obtained from three independent experiments, and 
Table 1 Operational parameters for HPLC, ICP-MS, and ESI-MS

\begin{tabular}{|c|c|}
\hline \multicolumn{2}{|l|}{ Settings } \\
\hline ICP-MS & Agilent 7500a \\
\hline RF Power & $1350 \mathrm{~W}$ \\
\hline Plasma, auxiliary, and nebulizer gas flow & 15.0, 1.0, and $1.05 \mathrm{~L} \mathrm{~min}^{-1}$ \\
\hline Cones & Sampler-Ni, Skimmer-Ni \\
\hline Monitored isotopes & ${ }^{59} \mathrm{Co}$ \\
\hline Dwell time & $0.1 \mathrm{~ms}$ \\
\hline \multicolumn{2}{|l|}{ HPLC separation } \\
\hline Pump & Agilent 1100 \\
\hline Column & Superdex $200(10 \times 300 \mathrm{~mm} \times 10 \mu \mathrm{m})$-GE Healthcare Life Sciences \\
\hline Mobile phase & 10 mM ammonium acetate buffer ( $\mathrm{pH} 7.4)$ \\
\hline Elution program & isocratic \\
\hline Flow & $0.7 \mathrm{~mL} \min ^{-1}$ \\
\hline Injection volume & $100 \mu \mathrm{L}$ \\
\hline Column temperature & $24^{\circ} \mathrm{C}$ \\
\hline Pump & Agilent 1200 Series \\
\hline Column & Zorbax SB C18 $(5 \mu \mathrm{m}, 4.6 \times 150 \mathrm{~mm})$ \\
\hline Mobile phase & $\begin{array}{l}\text { A: mixture water-methanol }(95: 5 \mathrm{v} / \mathrm{v}) \text { with } 0.1 \% \text { formic acid } \\
\text { B: mixture methanol-water }(95: 5 \mathrm{v} / \mathrm{v})\end{array}$ \\
\hline Injection volume $[\mu \mathrm{L}]$ & 0.2 \\
\hline Flow rate $\left[\mu \mathrm{L} \mathrm{min}^{-1}\right]$ & 5 \\
\hline Data acquisition mode & Time-resolved analysis (TRA) \\
\hline Integration time & $0.05-0.3 \mathrm{sec}$ \\
\hline \multicolumn{2}{|l|}{ ESI-MS detection } \\
\hline Detector & Agilent 6460 Triple Quad LC/MS with JetStream technology \\
\hline Polarity & Positive, negative \\
\hline Mode & SCAN, PI \\
\hline Ionization voltage [V] & 1500-2500 (PI), 1500-2500 (NI) \\
\hline Nebulizer pressure [psi] & $45-55$ \\
\hline Gas temperature $\left[{ }^{\circ} \mathrm{C}\right]$ & 300 \\
\hline Gas flow $\left[\mathrm{min}^{-1}\right]$ & 8 \\
\hline Sheath gas flow $\left[\mathrm{L} \mathrm{min}^{-1}\right]$ & $6-7$ \\
\hline Sheath gas temperature $\left[{ }^{\circ} \mathrm{C}\right]$ & $300-350$ \\
\hline Mass range, $\mathrm{m} / \mathrm{z}$ & 100-1500 (with HPLC) \\
\hline Collision energy, $\mathrm{V}$ & $5-30$ \\
\hline
\end{tabular}

the mean value of metal concentration was calculated. As the interest of this study, the following total amount of cobalt was established in açai berries $\left(0.348 \pm 0.042 \mu \mathrm{g} \mathrm{g}^{-1}\right)$, chia seeds $\left(0.352 \pm 0.036 \mu \mathrm{g} \mathrm{g}^{-1}\right)$, goji berries $(0.046 \pm$ $\left.0.003 \mu \mathrm{g} \mathrm{g}^{-1}\right)$, and bilberries $\left(0.082 \pm 0.010 \mu \mathrm{g} \mathrm{g}^{-1}\right)$. The results are in good agreement with the earlier studies reported by other authors in fruits and vegetables (Millour et al. 2011; Rybak and Ruzik 2013).

The RDA (recommended daily allowance) values for cobalt does not exist, there is no evidence that the intake of cobalt is ever limiting in the human diet. Normal daily intake is reported to be in the range of $2.5-3.0 \mathrm{mg}$ per day. Toxicity with cobalt has been reported to occur within the range of greater than $25-30 \mathrm{mg}$ cobalt daily (Hokin et al. 2004; Lauwerys and Lison 1994). However, the RDA value for vitamin $B_{12}$ provided by the Commission of the European is $2.5 \mu \mathrm{g}$ per day. This data was used for evaluation of extent the daily dosage of berries and chia seeds would provide a significant contribution to the diet. The daily dosage of açaí (100-150 g) and chia seeds $(40 \mathrm{~g})$ contributes to the normal daily intake of approximately $15 \%$ for cobalt which can also occur as 
a vitamin $B_{12}$, and other berries only $2-3 \%$. According to the results reported in this work, açaí and chia seeds are a good source of vitamin $B_{12}$ and could contribute to meeting the $B_{12}$ requirements for the human body.

Method validation Relative standard deviations among replicates of analysis of each sample were always lower than $10 \%$. Limit of detection (LOD) and limit of quantification (LOQ) were calculated for standard deviations (SD) of 10 measurements for blank, and it was found to be 0.024 and $0.073 \mu \mathrm{g} \mathrm{L}^{-1}$, respectively. The calibration equation achieved by ICP MS for cobalt was $y=8605 x-7.853$ with a correlation coefficient (r2) of 0.9997 . The total concentration of other trace elements in analyzed samples was also determined by authors, and the results are presented in previous studies (Ruzik and Wojcieszek 2016; Wojcieszek et al. 2017; Wojcieszek et al. 2016). The accuracy of the method was evaluated for the cobalt by spiking analyzed samples of chia seeds and berries with the standard of cobalt solution, and the total concentration of elements were carried out.
The appropriate standard solution was added to the three samples, and recovery values were between 75 and 103\%.

To get better knowledge about forms of cobalt present in analyzed food samples, extraction of cobalt species and their further characterization using hyphenated techniques has been performed.

\section{SEC-ICP-MS examination of extracts containing cobalt compounds}

The species containing cobalt (including the cobalamin forms) were separated according to their sizes and detected by ICP-MS, as described in the experimental section. The chromatographic run time was fixed on 60 min, but no peaks were observed at retention times higher than $31 \mathrm{~min}$. The SEC-ICP-MS elution profiles of cobalt extracted from analyzed samples (Fig. 1) show that Co is mainly bound to compounds that appear between 20 and $30 \mathrm{~min}$ of analysis, of molecular masses of $44.0-1.3 \mathrm{kDa}$, similar to studies describing the presence of cobalt in noni fruit (Rybak and Ruzik 2013) and cape

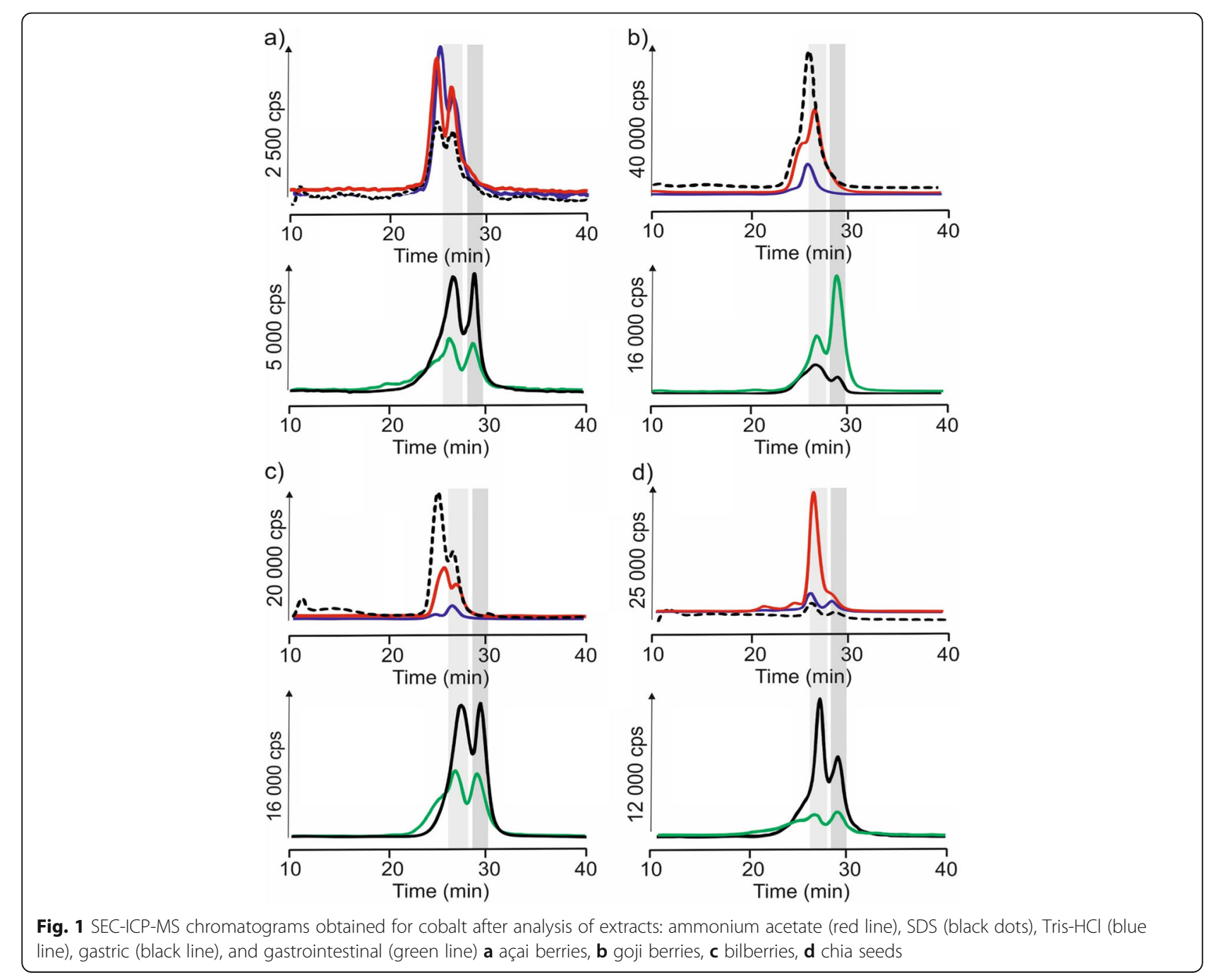


gooseberry (Wojcieszek and Ruzik 2016a). The results obtained for food samples revealed two peaks of cobalt for almost all analyzed extracts, with the most intense one detected in the low molecular mass region, registered after $25 \mathrm{~min}$ of the chromatographic process.

On the chromatograms of SDS extracts, also additional peaks were observed, probably corresponding to hydrophobic proteins bound to the investigated element. The peak at 11 min appears on the chromatograms of all analyzed food samples except that obtained for goji berries extract. The retention time is situated in the region of column's exclusion limit corresponding to high molecular weight compounds of at least $500 \mathrm{kDa}$, that could be explained by the ability of metal ions to form big agglomerates even with low molecular weight ligands. SDS is dedicated to the extraction of hydrophobic proteins that are suspected to create complexes with investigated elements (Połeć-Pawlak et al. 2005). However, it should be mentioned that due to the fact that aqueous solution of SDS was used for extraction, some peaks, especially those appearing in the region of low molecular mass compounds, can also correspond to water-soluble cobalt species.

When extraction was performed with the use of ammonium acetate, on the chromatograms of all analyzed foodstuffs, the peak at $27 \mathrm{~min}$ was observed, originated probably from water-soluble cobalt complexes. Column calibration allows finding that this peak corresponds to cobalt complexes with bioligands of molecular mass about $17.0 \mathrm{kDa}$. The additional peak appeared on chromatograms of all analyzed samples at $25 \mathrm{~min}$, but its peak areas are small, and its separation from other peak is not satisfactory in the case of chia seeds and goji berries. Another small peak registered on chromatograms of chia seeds extract at $21 \mathrm{~min}$ is absent on the chromatograms of other foodstuffs.

Tris- $\mathrm{HCl}$ was found to be not a very efficient extractant for cobalt complexes from analyzed samples comparing to SDS and ammonium acetate solutions. In general, no peaks were observed in the low molecular mass region of chromatograms, corresponding to cobalt complexes of molecular masses lower than $1.3 \mathrm{kDa}$.

Additionally, metal recovery from the SEC column was established by ICP-MS (as the ratio of metal injected onto the column to that in the collected eluate) as $92 \%$ for cobalt. On the other hand, the recoveries of cobalt from the SEC column obtained for tris extracts of berries and seeds were $94-105 \%$, obtained for SDS extracts were $89-103 \%$ and for ammonium acetate extracts about $89-107 \%$, depending on the fruit.

Trying to summarize, SEC-ICP-MS study shows that the greatest number of cobalt species (including the cobalamin forms) are extracted by SDS from bilberries and goji berries, and by ammonium acetate from chia seeds and açaí berries. It leads to the conclusion that the nature of bioligands complexing cobalt in analyzed berries and seeds is different. However, the used technique does not offer more detailed information concerning their chemical identity and this should be searched by another one, e.g., ESI-MS/MS (see below, "Confirmation of the presence of vitamin B12 by $\mu$-HPLC-ESI-MS analysis" section).

\section{Estimation of bioaccessibility of cobalt compounds by SEC-ICP-MS}

SEC-ICP-MS analysis of extracts obtained after simulation of gastrointestinal digestion with both pepsin and pancreatin was carried out under the same conditions as described above. On chromatograms of these extracts peak at $11 \mathrm{~min}$ (of high molecular mass compounds) was not observed it any case (Fig. 1).

Chromatograms of bilberries and açai berries obtained after enzymatic digestion were almost identical, showing two similar peaks at 26 and $29 \mathrm{~min}$. It suggests that during digestion of these berries, the same (or of very similar behavior) cobalt complexes are formed in the gastrointestinal tract and become available for the human organism. Both peaks correspond to low molecular mass cobalt complexes, $17.00-1.35 \mathrm{kDa}$, probably its conjugates with digestion products of peptides and proteins present in analyzed berries. A high affinity of cobalt ions to proteins and amino acids has already been reported (Paustenbach et al. 2013), and it was also found that enzymatic protein may interact with cobalt compounds (e.g., cobalamin) and improve their bioaccessibility (Lipiec et al. 2011).

In the case of chia seeds, the same peaks were observed on the chromatograms, but the intensity (and peak areas) of the second one, at $29 \mathrm{~min}$, was significantly less intense (for gastric digestion); gastrointestinal digestion both peaks on the chromatograms are definitively smaller. It leads to a conclusion that chia seeds are not a good source of cobalt compounds accessible for the human body after digestion.

The same two peaks appear on chromatograms of the extracts from goji berries after enzymatic digestion, but in this case, intensity and peak areas of signals of the gastrointestinal extract were significantly higher than those observed for gastric extract.

Concluding the study concerning bioaccessibility of cobalt compounds present in examined berries and seeds, one can find that among them goji berries offer the greatest amount of this element complexes undergoing digestion and potentially available for the human organism (the value of cobalt bioaccessibility is presented in Table 2). The differences among the bioaccessibility—for açaí and goji, the intestinal bioaccessibility is greater than the stomach values and for bilberries and chia, the opposite occurred-can be explained probably by the different other 
Table 2 Cobalt species observed in enzymatic extracts analyzed by $\mu$-HPLC-ESI-MS

\begin{tabular}{|c|c|c|c|c|c|}
\hline Sample & Enzyme & Bioaccessibility (\%) & $\boldsymbol{t}_{\mathrm{r}}(\mathrm{min})$ & Molecular formula & $(\boldsymbol{m} / \mathbf{z})$ \\
\hline \multirow[t]{6}{*}{ açaí berries } & pepsin & 63.4 & 23.7 & {$[\mathrm{Cbl}+\mathrm{H}]^{2+}$} & 665.2 \\
\hline & & & 29.4 & {$[\mathrm{CN}-\mathrm{Cbl}+2 \mathrm{H}]^{2+}$} & 678.1 \\
\hline & & & 27.3 & {$[\mathrm{Me}-\mathrm{Cbl}+\mathrm{H}]^{2+}$} & 673.2 \\
\hline & & & 27.3 & {$[\mathrm{Me}-\mathrm{Cbl}]^{+}$} & 1344.5 \\
\hline & pancreatin & 94.1 & 28.9 & {$[\mathrm{Cbl}+\mathrm{H}]^{2+}$} & 665.0 \\
\hline & & & 25.7 & {$[\text { Ado-Cbl }+\mathrm{H}]^{2+}$} & 790.4 \\
\hline \multirow[t]{6}{*}{ bilberries } & pepsin & 44.2 & 23.6 & {$[\mathrm{Cbl}+\mathrm{H}]^{2+}$} & 665.1 \\
\hline & & & 29.4 & {$[\mathrm{CN}-\mathrm{Cbl}+2 \mathrm{H}]^{2+}$} & 678.3 \\
\hline & & & 29.4 & {$[\mathrm{CN}-\mathrm{Cbl}+\mathrm{H}]^{+}$} & 1355.5 \\
\hline & & & 27.3 & {$[\mathrm{Me}-\mathrm{Cbl}]^{+}$} & 1344.5 \\
\hline & & & 25.7 & {$\left[\right.$ Ado-Cbl $+\mathrm{H}^{2+}$} & 790.4 \\
\hline & pancreatin & 32.1 & 28.7 & {$[\mathrm{Cbl}+\mathrm{H}]^{2+}$} & 665.0 \\
\hline \multirow[t]{3}{*}{ chia seeds } & pepsin & 56.1 & 29.3 & {$[\mathrm{CN}-\mathrm{Cbl}+2 \mathrm{H}]^{2+}$} & 678.7 \\
\hline & & & 25.9 & {$[\text { Ado-Cbl }+\mathrm{H}]^{2+}$} & 790.3 \\
\hline & pancreatin & 37.4 & - & - & - \\
\hline \multirow[t]{8}{*}{ goji berries } & pepsin & 86.2 & 27.4 & {$[\mathrm{Me}-\mathrm{Cbl}+\mathrm{H}]^{2+}$} & 673.3 \\
\hline & pancreatin & 91.4 & 28.8 & {$[\mathrm{Cbl}+\mathrm{H}]^{2+}$} & 665.1 \\
\hline & & & 27.3 & {$[\mathrm{Me}-\mathrm{Cbl}+\mathrm{H}]^{2+}$} & 673.0 \\
\hline & & & \multicolumn{3}{|l|}{ standards } \\
\hline & & & 23.6 & {$[\mathrm{Cbl}+\mathrm{H}]^{2+}$} & 665.1 \\
\hline & & & 27.2 & {$[\mathrm{Me}-\mathrm{Cbl}]^{+} /[\mathrm{Me}-\mathrm{Cbl}+\mathrm{H}]^{+}$} & $637.2 / 1344.5$ \\
\hline & & & 25.7 & {$[\text { Ado-Cbl }+\mathrm{H}]^{2+}$} & 790.3 \\
\hline & & & 29.4 & {$[\mathrm{CN}-\mathrm{Cbl}+2 \mathrm{H}]^{+} /[\mathrm{CN}-\mathrm{Cbl}+\mathrm{H}]^{+}$} & $678.1 / 1355.5$ \\
\hline
\end{tabular}

fruit ingredients and the occurrence of various complexing factors in the plant.

\section{Sequential extraction of cobalt compounds from goji berries}

In previous studies (Fig. 1a, b, c, d), it was observed that exclusively on the chromatogram of SDS extracts from goji berries only one peak is registered. Their behavior in the course of enzymatic digestion also is different than of another examined foodstuffs (chromatograms 1). Additionally, taking into account that this product probably offers more bioaccessible forms of cobalt than others, it was examined with greater care.

For more detailed study, sequential extraction has been chosen. It was performed with three solutions used in the following order: (i) $10 \mathrm{mM}$ ammonium acetate (pH 6.8), (ii) $30 \mathrm{mM}$ Tris- $\mathrm{HCl}$ (pH 7.4), (iii) $2 \%$ SDS. In the first step extraction of low molecular mass, watersoluble compounds of cobalt were expected. The last extraction, with SDS solution, was used to separate cobalt complexes of high molecular mass, probably with hydrophobic proteins. Typically for a sequential procedure, the next extractant was added not to the fresh sample but the residue left after the previous extraction.
On the chromatograms (Fig. 2) of ammonium acetate (1st step) and Tris-HCl (2nd step) extracts of goji berries, one peak in the low molecular mass region was observed. The intensity of the peak registered for ammonium acetate extract was higher, which can suggest, that most of the water-soluble cobalt complexes can be extracted in this step. SDS solution extracts, according to expectations, high molecular mass fractions appeared as one, low intense peak on the chromatogram. Such low intensity of this peak suggests that in goji berries only a small amount of cobalt is bound to compounds of higher masses.

Results of the study, as well as those obtained in SEC experiments, indicate that for further examination of complicated matrices of foodstuffs, it is necessary to elaborate efficient method for characterization of trace amounts of cobalt species, e.g., $\mu$-HPLC-ESI-MS protocol.

\section{Confirmation of the presence of vitamin $B_{12}$ by $\mu$-HPLC- ESI-MS analysis}

As it was mentioned in the "Introduction" section, the most important for human organisms cobalt species are cobalamin derivatives and because of it a simple $\mu$ - 


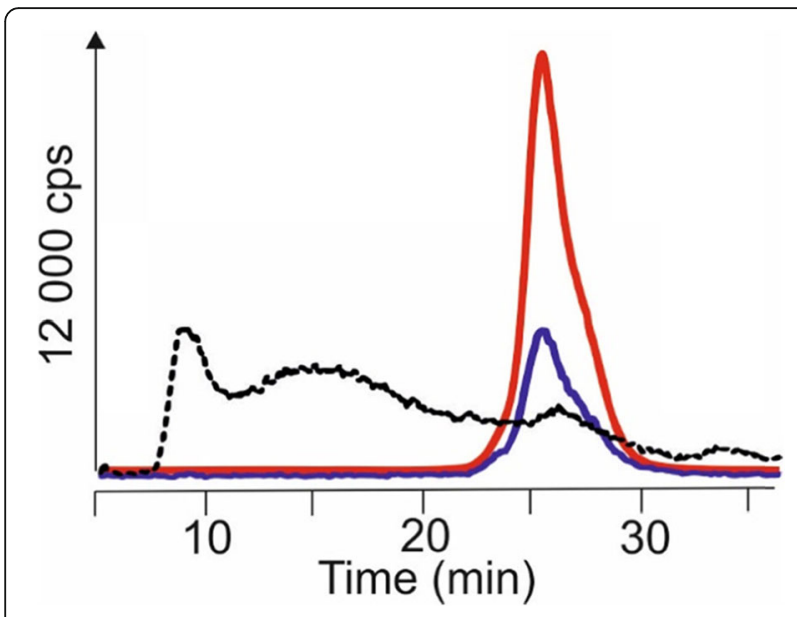

Fig. 2 SEC-ICP-MS chromatograms obtained after sequential extraction of cobalt compounds from goji berries: 1st step_ammonium acetate (red line), 2nd step-tris-HCl (black dots), and 3rd step-SDS (black dots)

HPLC-ESI-MS method (Wojcieszek et al. 2015) for the identification of vitamin $B_{12}$ in bilberries, goji berries, açai berries, and chia seeds, after simulation of gastrointestinal digestion with both pepsin and pancreatin, has been presented. Cobalamin species observed after enzymatic digestion of analyzed samples are presented in Table 2. However, in obtained scan mode mass spectra, the cobalt species were observed only when the positiveion mode was used.

Among the examined products, bilberries were found as the richest in cobalt species. The presence of biological forms of cobalamin - methylcobalamin and adenosylcobalamin (also known as coenzyme $\mathrm{B}_{12}$ ) - was confirmed by two peaks observed in the mass spectrum, at $m / z 1345$ and 790, respectively. The protonated $\mathrm{CN}-\mathrm{Cbl}^{+}$ion at $m / z 678$ and the native $\mathrm{CN}-\mathrm{Cbl}^{+}$ion at $\mathrm{m} / z 1355$ corresponding to the cyanocobalamin were observed after gastric digestion. The unexpected presence of cyanocobalamin in bilberries may create a basis for the hypothesis, that plantation of analyzed bilberries could be fortified by vitamin $B_{12}$.

It is important to mention that after the end of the process of gastrointestinal digestion, the signal at $\mathrm{m} / \mathrm{z}$ 665 was observed in the registered mass spectra, corresponding to cobalamin. It can be concluded that during the simulation of gastrointestinal digestion, the $\beta$-ligands (Ado-, $\mathrm{Me}-$ or $\mathrm{CN}-$ ) are probably lost and only one form of cobalamin could be identified.

The comparable conclusion can be drawn in the case of açai berries-in the mass spectrum of their enzymatic extract also signal at 679 (cyanocobalamin) was present. In this foodstuff, also methylcobalamin was found (confirmed by signals at $\mathrm{m} / \mathrm{z} 673$ and 1344). Moreover, in the gastrointestinal extract, the signal at $\mathrm{m} / \mathrm{z} 790$ could be also observed, corresponding to coenzyme $\mathrm{B}_{12}$.
Nevertheless, in enzymatic extracts of chia seeds, two forms of cobalamin could be identified only in gastric one-cyanocobalamin (signal at $\mathrm{m} / \mathrm{z}$ 678) and adenosylcobalamin $(\mathrm{m} / \mathrm{z} 790)$. We could not observe cobalt species after the gastrointestinal digestion.

Moreover, in goji berries, only methylcobalamin could be identified after the gastric digestion. Additionally, after the end of the process of gastrointestinal digestion, only methylcobalamin and cobalamin could be observed.

\section{Conclusions}

SEC-ICP-MS and $\mu$-HPLC-ESI-MS were found to be useful tools for the examination of cobalt speciation in berries and seeds. Chromatographic profiles (SEC-ICP MS) of extracts obtained with the use of different extraction media (ammonium acetate, Tris-HCl, SDS) allows drawing conclusions dealing with different nature of biologically active compounds binding cobalt. Three-step sequential extraction protocol allows for obtaining high molecular mass cobalt species from berries in the third step, performed with aqueous SDS solution (two first steps remove watersoluble compounds). For the identification of cobalamin (vitamin $\mathrm{B}_{12}$-the only form of cobalt being absorbed by the human organism) analogs in examined foodstuffs, the developed $\mu$-HPLC-ESI-MS procedure can be recommended. The elaborated methods may be used as a simple tool for studying metal speciation in various foodstuffs.

\section{Abbreviations}

$\mu$-HPLC-ESI-MS/MS: $\mu$-high-performance liquid chromatography coupled to electrospray ionization tandem mass spectrometry; Ado-

Cbl: Adenosylcobalamin; ICP-MS: Inductively coupled plasma mass spectrometry; LC-MS: Liquid chromatography-mass spectrometry; LOD: Limit of detection; LOQ: Limit of quantification; Me-Cbl: Methylcobalamin; $\mathrm{OH}-$

Cbl: Hydroxocobalamin; PTFE: Polytetrafluoroethylene; RDA: Recommended daily allowance; SD: Standard deviations; SEC: Size exclusion chromatography

\section{Acknowledgments}

The authors are thankful to the Warsaw University of Technology for the financial support of the presented study.

\section{Authors' contributions}

JW and LR performed the measurements: JW the ICP MS study and LR the ESI MS study. JW and LR processed the experimental data and performed the analysis. LR drafted the manuscript and designed the figures. LR and JW aided in interpreting the results and worked on the manuscript. Both JW and $L R$ authors contributed to the final version of the manuscript. The authors read and approved the final version of the manuscript.

\section{Funding}

Not applicable

\section{Availability of data and materials}

Not applicable

\section{Competing interests}

The authors declare no conflicts of interest. 
Received: 10 March 2020 Accepted: 24 June 2020

Published online: 07 July 2020

\section{References}

Adolfo FR, Do Nascimento PC, Bohrer D, De Carvalho LM, Viana C, Guarda A, et al. Simultaneous determination of cobalt and nickel in vitamin B12 samples using high-resolution continuum source atomic absorption spectrometry. Talanta. 2016;147:241-5.

Altundag H, Albayrak S, Dundar MS, Tuzen M, Soylak M. Investigation of the influence of selected soil and plant properties from Sakarya, Turkey, on the bioavailability of trace elements by applying an in vitro digestion model. Biol. Trace Elem. Res. 2015;168(1):276-85.

Bosle J, Goetz S, Raab A, Krupp EM, Scheckel KG, Lombi E, et al. Cobalamin concentrations in fetal liver show gender differences: a result from using a high-pressure liquid chromatography - inductively coupled plasma mass spectrometry as an ultratrace cobalt speciation method. Anal. Chem. 2016; 88(24):12419-26.

Chu W, Cheung SCM, Lau RAW, Benzie IFF. Chapter 4 Bilberry (Vaccinium myrtillus L.). Herb. Med. Biomol. Clin. Asp. [Internet]. 2010;1-18. Available from: http://www.ncbi.nlm.nih.gov/pubmed/22593936

Heinrich M, Dhanji T, Casselman I. Açai (Euterpe oleracea Mart.)—a phytochemical and pharmacological assessment of the species' health claims. Phytochem. Lett. [Internet]. 2011;4(1):10-21. Available from: https:// doi.org/10.1016/.jphytol.2010.11.005\%5Cnhttp://linkinghub.elsevier.com/ retrieve/pii/S1874390010001096.

Hokin B, Adams M, Ashton J, Louie H. Comparison of the dietary cobalt intake in three different Australian diets. Asia Pac. J. Clin. Nutr. 2004;13(3):289-91.

Howlett GJ, Minton AP, Rivas G. Analytical ultracentrifugation for the study of protein association and assembly. Curr. Opin. Chem. Biol. 2006:430-6.

Indyk HE, Persson BS, Caselunghe MCB, Moberg A, Filonzi EL, Woollard DC. Determination of vitamin B12 in milk products and selected foods by optical biosensor protein-binding assay: method comparison. AOAC International; [cited 2017 Oct 3]; Available from: http://aoac.publisher.ingentaconnect.com/ contentone/aoac/jaoac/2002/00000085/00000001/art00014\#expand/collapse.

Intawongse $\mathrm{M}$, Dean JR. In-vitro testing for assessing oral bioaccessibility of trace metals in soil and food samples. TrAC - Trends Anal. Chem. 2006;25(9):876-86.

Kannamkumarath SS, Wuilloud RG, Caruso JA. Studies of various elements of nutritional and toxicological interest with different molecular weight fractions in Brazil nuts. J. Agric. Food Chem. 2004:52(19):5773-80.

Khouzam RB, Pohl P, Lobinski R. Bioaccessibility of essential elements from white cheese, bread, fruit and vegetables. Talanta. 2011:86(1):425-8.

Koplík R, Borková M, Mestek O, Komínková J, Suchánek M. Application of sizeexclusion chromatography-inductively coupled plasma mass spectrometry for fractionation of element species in seeds of legumes. J. Chromatogr. B Anal. Technol. Biomed. Life Sci. 2002a:179-87.

Koplík R, Pavelková H, Cincibuchová J, Mestek O, Kvasnička F, Suchánek M. Fractionation of phosphorus and trace elements species in soybean flour and common white bean seeds by size exclusion chromatographyinductively coupled plasma mass spectrometry. J. Chromatogr. B Anal. Technol. Biomed. Life Sci. 2002b;770(1-2):261-73.

Kumar SS, Chouhan RS, Thakur MS. Trends in analysis of vitamin B12. Anal. Biochem. 2010:139-49.

Lauwerys R, Lison D. Health risks associated with cobalt exposure - an overview. Sci. Total Environ. 1994;150(1-3):1-6.

Lipiec E, Ruzik L, Zhou Y, Jarosz M, Połeć-Pawlak K. Study of chicken egg protein influence on bioavailability of vitamin B12 by SEC-ICP MS and ESI MS. J. Anal. At. Spectrom. 2011;26(3):608

Lipiec E, Warowicka O, Ruzik L, Zhou Y, Jarosz M, Połeć-Pawlak K. Investigation of iodine bioavailability from chicken eggs versus iodized kitchen salt with in vitro method. Eur. Food Res. Technol. 2012;234(5):913-9.

Luten JB, Bouquet W, Burggraaf M, Rus J. In: Schramel P, Bratter P, editors. Trace element analytical chemistry in medicine and biology. Walter de Gruyter: Berlin; 1987.

Millour S, Noël L, Kadar A, Chekri R, Vastel C, Guérin T. Simultaneous analysis of 21 elements in foodstuffs by ICP-MS after closed-vessel microwave digestion: method validation. J. Food Compos. Anal. [Internet]. Academic Press; 2011 Feb 1 [cited 2020 Apr 28];24(1):111-20. Available from: https://www. sciencedirect.com/science/article/abs/pii/S0889157510001730.

Muñoz LA, Cobos A, Diaz O, Aguilera JM. Chia seed ( Salvia hispanica ): an ancient grain and a new functional food. Food Rev. Int [Internet]. 2013:29(4):394-408. Available from: http:/www.tandfonline.com/doi/abs/10.1080/87559129.2013.818014.
Nakos M, Pepelanova I, Beutel S, Krings U, Berger RG, Scheper T. Isolation and analysis of vitamin B12 from plant samples. 2016 [cited 2020 Apr 29]; Available from: https://doi.org/10.1016/j.foodchem.2016.08.037.

Namiesnik J, Vearasilp K, Kupska M, Ham KS, Kang SG, Park YK, et al. Antioxidant activities and bioactive components in some berries. Eur. Food Res. Technol. 2013:1-11.

Ng JC, Juhasz A, Smith E, Naidu R. Assessing the bioavailability and bioaccessibility of metals and metalloids. Environ. Sci. Pollut. Res. 2015;22(12):8802-25.

Paustenbach DJ, Tvermoes BE, Unice KM, Finley BL, Kerger BD. A review of the health hazards posed by cobalt. Crit. Rev. Toxicol. [Internet]. 2013;43(4):316-362. Available from: http:/www.tandfonline.com/doi/full/10.3109/10408444.2013.779633.

Peixoto RRA, Devesa V, Vélez D, Cervera ML, Cadore S. Study of the factors influencing the bioaccessibility of 10 elements from chocolate drink powder. J. Food Compos. Anal. 2016;48:41-7.

Połeć-Pawlak K, Ruzik R, Abramski K, Ciurzyńska M, Gawrońska H. Cadmium speciation in Arabidopsis thaliana as a strategy to study metal accumulation system in plants. Analytica Chimica Acta. 2005;540(1):61-70. https://doi.org/ 10.1016/j.aca.2004.10.048.

Połeć-Pawlak K, Ruzik R, Lipiec E. Investigation of Cd(II), Pb(II) and Cu(I) complexation by glutathione and its component amino acids by ESI-MS and size exclusion chromatography coupled to ICP-MS and ESI-MS. Talanta. 2007;72(4):1564-72.

Ruzik L, Wojcieszek J. In vitro digestion method for estimation of copper bioaccessibility in Açaí berry. Monatshefte fur Chemie. 2016;147(8).

Rybak J, Ruzik L. Application of chromatography and mass spectrometry to the characterization of cobalt, copper, manganese and molybdenum in Morinda Citrifolia. J. Chromatogr. A [Internet]. Elsevier B.V.; 2013;1281:19-25. Available from: https://doi.org/10.1016/j.chroma.2013.01.040.

Sadi BBM, Wrobel K, Wrobel K, Kannamkumarath SS, Castillo JR, Caruso JA. SECICP-MS studies for elements binding to different molecular weight fractions of humic substances in compost extract obtained from urban solid waste. J. Environ. Monit. 2002;4(6):1010-6.

Stoica A-I, Peltea M, Baiulescu G, Ionica M. Determination of cobalt in pharmaceutical products. J. Pharm. Biomed. Anal. 2004;36:653-6.

Szpunar J, Łobiński R. Multidimensional approaches in biochemical speciation analysis. Anal. Bioanal. Chem. 2002:404-11.

Wang CC, Chang SC, Inbaraj BS, Chen BH. Isolation of carotenoids, flavonoids and polysaccharides from Lycium barbarum $L$. and evaluation of antioxidant activity. Food Chem. [Internet]. Elsevier Ltd; 2010;120(1):184-192. Available from: http://linkinghub.elsevier.com/retrieve/pii/S030881460901 1832.

Watanabe F. Vitamin B12 sources and bioavailability. Exp. Biol. Med. [Internet]. 2007;232(10):1266-1274. Available from: http://ebm.rsmjournals.com/cgi/ doi/10.3181/0703-MR-67.

Watanabe F, Bito T. Vitamin B12 sources and microbial interaction. Exp. Biol. Med. [Internet]. SAGE Publications; 2018 [cited 2020 Apr 29];243(2):148. Available from: https://www-1ncbi-1nlm-1nih-1gov-10000abak1801.eczyt.bg.pw.edu.pl/ pmc/articles/PMC5788147/.

Watanabe F, Yabuta Y, Bito T, Teng F. Vitamin B12-containing plant food sources for vegetarians. Nutrients [Internet]. Multidisciplinary Digital Publishing Institute (MDPI); 2014 May 5 [cited 2020 Apr 28];6(5):1861-73. Available from: http://www.ncbi.nlm.nih.gov/pubmed/24803097.

Wojcieszek J, Kwiatkowski P, Ruzik L. Speciation analysis and bioaccessibility evaluation of trace elements in goji berries ( Lycium Barbarum , L .) \&. J. Chromatogr. A [Internet]. Elsevier B.V.; 2017;1492:70-78. Available from: https://doi.org/10.1016/j.chroma.2017.02.069.

Wojcieszek J, Popowski D, Ruzik L. Ionic liquids as a key medium for efficient extraction of copper complexes from chia seeds (Salvia hispanica L.). Talanta [Internet]. Elsevier; 2016;152:482-488. Available from: http://linkinghub. elsevier.com/retrieve/pii/S0039914016301175.

Wojcieszek J, Ruzik L. Operationally defined species characterization and bioaccessibility evaluation of cobalt, copper and selenium in Cape gooseberny (Physalis Peruviana L.) by SEC-ICP MS. J. Trace Elem. Med. Biol. 2016a:34.

Wojcieszek J, Ruzik L. Enzymatic extraction of copper complexes with phenolic compounds from Açaí (Euterpe oleracea Mart.) and bilberry (Vaccinium myrtillus L.) fruits. Food Anal. Methods. 2016b;9(7).

Wojcieszek J, Witkoś K, Ruzik L, Pawlak K. Comparison of copper and zinc in vitro bioaccessibility from cyanobacteria rich in proteins and a synthetic supplement containing gluconate complexes: LC-MS mapping of bioaccessible copper complexes. Anal. Bioanal. Chem. 2015;408(3):1-11.

\section{Publisher's Note}

Springer Nature remains neutral with regard to jurisdictional claims in published maps and institutional affiliations. 